\title{
Oomicetos do Parque Estadual da Serra da Cantareira, São Paulo, SP, Brasil
}

\author{
Maria Luiza de Miranda ${ }^{1}$ e Carmen Lidia Amorim Pires-Zottarelli1,2
}

Recebido: 19.04.2010; aceito: 8.03.2012

\begin{abstract}
Oomycetes from the "Parque Estadual da Serra da Cantareira", São Paulo, São Paulo State, Brazil). To contribute to the knowledge of Oomycetes of the Brazilian Atlantic rainforest, water and soil samples were collected, every three months, from June/2005 to June/2006, in the Parque Estadual da Serra da Cantareira, São Paulo State, Brazil. The samples were treated with the multiple baiting technique, in the laboratory and in the field, to isolate these organisms. Twentyone species were identified, two of Leptomitales and 19 of Saprolegniales, with 179 occurrences during the studied period. Key words: Atlantic Rainforest, diversity, zoosporic organisms
\end{abstract}

RESUMO - (Oomicetos do Parque Estadual da Serra da Cantareira, São Paulo, SP, Brasil). Visando contribuir para o conhecimento da diversidade de oomicetos de áreas de Mata Atlântica do Brasil, amostras de água e solo foram coletadas trimestralmente, de junho de 2005 a junho de 2006, no Parque Estadual da Serra da Cantareira, São Paulo, Brasil. Para o isolamento destes organismos, as amostras foram submetidas à técnica de iscagem múltipla, em laboratório e em campo. Vinte e uma espécies foram identificadas, duas pertencentes a Leptomitales e 19 a Saprolegniales, com 179 ocorrências ao longo do período de estudo.

Palavras-chave: diversidade, Mata Atlântica, organismos zoospóricos

\section{Introdução}

Os oomicetos são organismos zoospóricos heterotróficos presentes em diversos ecossistemas aquáticos e terrestres, onde atuam como sapróbios e/ou parasitas. Segundo Kirk et al. (2008), são classificados como pertencentes ao Reino Chromista, filo Oomycota, classe Oomycetes, a qual possui 13 ordens, 25 famílias, 106 gêneros e 956 espécies. Estudos taxonômicos com estes organismos em áreas de Mata Atlântica ainda são poucos se considerarmos a amplitude e importância deste bioma, entretanto, este ainda é um dos mais estudados quando comparado aos outros biomas brasileiros, com relato em literatura de 87 espécies (Beneke \& Rogers 1962, Furtado 1965, Rogers et al. 1970, Lyra \& Milanez (1974), Milanez \& Trufem $(1981,1984)$, Schoenlein-Crusius \& Milanez (1989), Schoenlein-Crusius et al. (1992), Milanez et al. 1994, 1996, Pires-Zottarelli et al. 1996, Rocha \& Pires-Zottarelli 2002, Gomes \& Pires-Zottarelli 2006, 2008, Pires-Zottarelli \& Rocha 2007, Pires-Zottarelli et al. 2007).
Os estudos até agora realizados com os oomicetos no Brasil permitiram o conhecimento de aproximadamente $10 \%$ dos táxons registrados para o mundo, percentual considerado ainda muito baixo para um país tropical, rico em biodiversidade. Para o Parque Estadual da Serra da Cantareira relatamos a ocorrência e distribuição do gênero Pythium, o qual agrupa muitas espécies de importância fitopatológica (Miranda \& Pires-Zottarelli 2008). Com o objetivo de contribuir para o conhecimento da diversidade dos oomicetos, apresentamos neste artigo, descrição, comentários e fotomicrografias de espécies de Leptomitales e Saprolegniales.

\section{Material e métodos}

O Parque Estadual da Serra da Cantareira $\left(23^{\circ} 32^{\prime} 36^{\prime}\right.$ S e $\left.46^{\circ} 37^{\prime} 59^{\prime} \mathrm{W}\right)$ é um importante fragmento de Mata Atlântica localizado no estado de São Paulo, sendo considerada a maior unidade de conservação do mundo em perímetro urbano. Com área aproximada de 7.916 ha, abrange quatro

1. Instituto de Botânica, Núcleo de Pesquisa em Micologia, Caixa Postal 68041, CEP 04045-972 São Paulo, SP, Brasil.

2. Autor para correspondência: zottarelli@uol.com.br 
municípios, São Paulo, Caieiras, Mairiporã e Guarulhos, estando atualmente sob jurisdição do Instituto Florestal do Estado de São Paulo (Rocha \& Costa 1998). O Parque está dividido em quatro núcleos, Águas Claras, Cabuçu, Engordador e Pedra Grande, sendo o "Engordador" o escolhido para estudo devido à grande quantidade de corpos d'água existentes no local.

Para o estudo da diversidade dos oomicetos, foram realizadas coletas trimestrais de amostras de solo e água (35 de cada compartimento), no período de junho de 2005 a junho de 2006, em sete pontos amostrais previamente estabelecidos no Parque. Duas técnicas de iscagem descritas em Milanez (1989) foram utilizadas para o isolamento de representantes do grupo, as quais consistem na utilização de substratos celulósicos, queratinosos e quitinosos, em campo e em laboratório, os quais atuam como "iscas". Após isolamento e purificação dos táxons, a qual envolveu o crescimento dos espécimes em novos substratos e/ou meio de cultura MP5 (Beneke \& Rogers 1962), os espécimes foram identificados com literatura específica e documentados por meio de equipamento de captura de imagem Leica Qwin V3.

Lâminas semi-permanentes foram preparadas com azul de algodão e lactofenol, vedadas com esmalte incolor, para incorporação dos espécimes no Herbário do Instituto de Botânica de São Paulo (SP) e/ou preservados em frascos Wheaton, com água destilada e esterilizada e metades de sementes de Sorghum sp., em câmara fria (Milanez 1989), pelo método de Castellani (Figueiredo \& Pimentel 1975), e em tubos de ensaio com meio de cultura, para incorporação na Coleção de Culturas de algas, fungos e cianobactérias do Instituto de Botânica (CCIBt antiga SPC).

A frequência (\%) dos espécimes no período de estudo foi calculada levando-se em consideração sua ocorrência e distribuição ao longo dos meses de coleta.

\section{Resultados e Discussão}

De cinco coletas realizadas de junho/2005 a junho/2006, vinte e uma espécies foram identificadas, sendo duas pertencentes a Leptomitales, Leptolegniellaceae e 19 a Saprolegniales, seis a Leptolegniaceae e 13 a Saprolegniaceae (tabela 1), com o registro de 179 ocorrências. Todos os táxons identificados são citados pela primeira vez para a área de estudo, no entanto, já foram relatados em áreas de Mata Atlântica do Estado de São Paulo.

\section{FILO OOMYCOTA \\ OOMYCETES \\ LEPTOMITALES \\ LEPTOLEGNIELLACEAE}

Leptolegniella exogena Karling, Nova Hedwigia 45 (3/4): 433. 1987.

Figura 1

Micélio intramatrical em ecdise de cobra; hifas irregulares. Zoosporângios indiferenciados do micélio vegetativo. Zoósporos esféricos, emergindo para fora da hifa para a formação dos esporos de resistência. Esporos de resistência esféricos, exógenos, 15-22,5 $\mu \mathrm{m}$ diâm.

Material examinado: BRASIL. São Paulo: Parque Estadual da Serra da Cantareira, sapróbia em ecdise de cobra, amostras de solo, 13-XII-2005, M.L. Miranda s.n. (SP381891).

As características do espécime estudado estão de acordo com a descrição de Karling (1987). Gomes \& Pires-Zottarelli (2006) relataram a primeira ocorrência da espécie no país em área de Mata Atlântica da Reserva Biológica de Paranapiacaba, Santo André (SP).

Leptolegniella keratinophila Huneycutt, J. Elisha Mitchell Sci. Soc. 68: 110. 1952.

Figuras 2-4

Micélio intramatrical e extensivo em ecdise de cobra; hifas irregulares, ramificadas, 10-15 $\mu \mathrm{m}$ espessura. Zoosporângios indiferenciados do micélio vegetativo. Esporos de resistência localizados internamente nas hifas do micélio vegetativo, esféricos, 15-22,5 $\mu \mathrm{m}$ diâm., ocasionalmente ovais, 17,5-22,5 × 15-20 $\mu \mathrm{m}$ diâm., gotícula lipídica excêntrica.

Material examinado: BRASIL. São PAULO: Parque Estadual da Serra da Cantareira, sapróbia em ecdise de cobra, amostras de solo, 21-IX-2005, 31-III-2006, 12-VI-2006, M.L. Miranda s.n. (SP381892).

Esporos de resistência formados dentro das hifas é a característica marcante da espécie. Os espécimes estudados apresentaram esporos de resistência maiores que os relatados por Huneycutt (1952), Milanez (1970), Pires-Zottarelli et al. (1996) e Gomes \& Pires-Zottarelli (2008), variação normalmente verificada entre os espécimes. As demais características não diferiram. 
Tabela 1. Oomicetos isolados de água e solo do Parque Estadual da Serra da Cantareira de junho/2005 a junho/2006. (F: frequência).

Table 1. Oomycetes isolated from water and soil of the Parque Estadual da Serra da Cantareira from June/2005 to June/2006. (F: frequency).

\begin{tabular}{lllllll}
\hline Táxons/Meses & jun/05 & set/05 & dez/05 & mar/06 & jun/06 & $N^{\circ}$ de isolados \\
\hline
\end{tabular}

Reino Chromista

Oomycetes

Oomycota

Leptomitales

Leptolegniellaceae

Leptolegniella exogena

L. keratinophila

1

1

$2-2$

20

2

60

Saprolegniales

Leptolegniaceae

Aphanomyces helicoides

A. stellatus

2

Leptolegnia eccentrica

L. subterranea

Plectospira myriandra

$\begin{array}{ll}2 & 2 \\ 2 & \\ 1 & 1 \\ 1 & 2 \\ 1 & \end{array}$

2
1
1

6

3

100

1

20

80

40

7

8

60

Saprolegniaceae

Achlya apiculata

A. caroliniana

A. flagellata

A. klebsiana

A. orion

A. oviparvula

A. prolifera

A. radiosa

Dictyuchus pseudodictyon

Phragmosporangium uniseriatum

Pythiopsis humphreyana

$\begin{array}{ll} & 1 \\ 4 & 2 \\ 3 & 3 \\ & 2 \\ 1 & 2 \\ 1 & 5 \\ 1 & 2 \\ 5 & 4 \\ 7 & 5 \\ 6 & 3 \\ 3 & 6 \\ 1 & \\ 1 & \\ 3 & 1\end{array}$

4
2
1

2
4
2
3

2

40

60

100

60

80

60

60

100

Saprolegnia diclina

S. parasitica

3

100

100

80

20

20

Thraustotheca clavata

\begin{tabular}{lllllll}
\hline Total de ocorrências & 43 & 42 & 23 & 31 & 40 & 179 \\
\hline Total de táxons & 17 & 16 & 11 & 10 & 13 & 21 \\
\hline
\end{tabular}



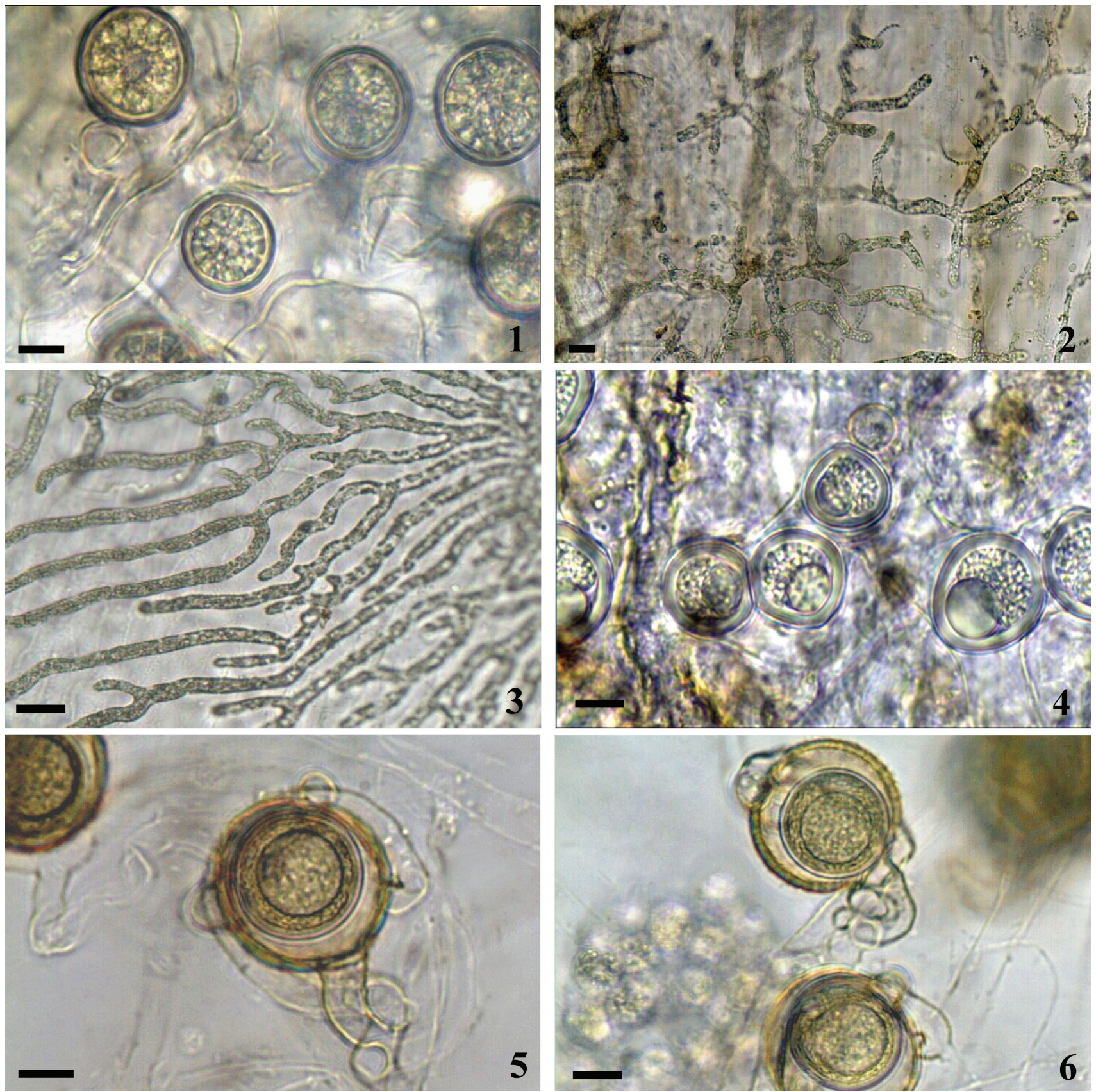

Figuras 1-6. Oomicetos do Parque Estadual da Serra da Cantareira. 1. Leptolegniella exogena Karling. Esporos de resistência exógenos. 2-4. Leptolegniella keratinophila Huneycutt. 2-3. Aspecto geral do talo. 4. Esporos de resistência formados dentro do micélio. 5-6. Aphanomyces helicoides von Minden. 5. Oogônio com oósporo subcêntrico e anterídio enrolando no pedúnculo oogonial e atracando no oogônio. 6. Tubo de fertilização. Barras $=10 \mu \mathrm{m}$ para as figuras 1, 3, 4, 5 e 6 . Barras $=20 \mu \mathrm{m}$ para a figura 2.

Figures 1-6. Oomycetes from the Parque Estadual da Serra da Cantareira. 1. Leptolegniella exogena Karling. Exogenous resting spores. 2-4. Leptolegniella keratinophila Huneycutt. 2-3. General aspect of the thallus. 4. Resting spores into the mycelium. 5-6. Aphanomyces helicoides von Minden. 5. Oogonium with subcentric oospore and antheridium surrounding the oogonia. 6 . Fertilization tube. Bars $=10 \mu \mathrm{m}$ to the figures $1,3,4,5$ and 6 . Bars $=20 \mu \mathrm{m}$ to the figure 2 . 


\section{SAPROLEGNIALES LEPTOLEGNIACEAE}

Aphanomyces helicoides von Mindem, Krypt.-Fl. Brandenburg 5: 559. 1915.

Figuras 5-6

Talo monóico. Micélio limitado; hifas delicadas. Zoosporângios filamentosos, longos. Zoósporos primários dispostos em uma fileira simples no zoosporângio; liberação aclióide. Oogônios laterais, esféricos, 32,5-40 $\mu \mathrm{m}$ diâm., às vezes ovais, de coloração amarelada. Anterídios presentes; ramos anteridiais díclinos, raramente monóclinos; simples, enrolando no pedúnculo oogonial; célula anteridial simples; atracação lateral; tubo de fertilização não observado. Oósporos de coloração amarelada, subcêntricos, esféricos, 25-30 $\mu \mathrm{m}$ diâm.; parede do oósporo de 2,0-2,5 $\mu \mathrm{m}$ de espessura.

Material examinado: BRASIL. São Paulo: Parque Estadual da Serra da Cantareira, sapróbio em semente se sorgo, amostras de água e solo, 8-VI-2005, 21-IX-2005, 13-XII-2005, 31-III-2006, 12-VI-2006, M.L. Miranda s.n. (CCIBt2116).

Coloração amarelada dos oogônios e dos oósporos e a presença de ramos anteridiais enrolando no pedúnculo oogonial são as características marcantes da espécie. As características do espécime estudado concordam com Scott (1961).

Aphanomyces stellatus de Bary, Jb. wiss. Bot. 2: 178. 1860.

Figuras 7-9

Talo monóico. Micélio delicado em ecdise de cobra. Zoosporângios filamentosos, longos. Zoósporos primários dispostos em uma fileira simples no zoosporângio; liberação aclióide. Oogônios terminais ou laterais, esféricos 27-40,5 $\mu$ m diâm., com ornamentações tuberculadas, papiladas ou truncadas, 3-7,5 $\mu \mathrm{m}$ compr. Anterídios presentes; ramos anteridiais díclinos ou andróginos; pedúnculo simples; atracação lateral ou apical; tubo de fertilização não observado. Oosferas maturando. Oósporos com gotículas lipídicas subcêntricas e cêntricas, esféricos, 17,5-22,5 ㅆm diâm.; 1 por oogônio.

Material examinado: BRASIL. São Paulo: Parque Estadual da Serra da Cantareira, sapróbio em ecdise de cobra, amostras de água, 8-VI-2005, 13-XII-2005, M.L. Miranda s.n. (SP381890).

Oogônios com ornamentações tuberculadas, papiladas ou truncadas são as principais características da espécie. Os espécimes apresentaram oogônios maiores e oósporos menores quando comparados com Johnson et al. (2002), que citam, respectivamente,

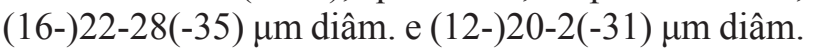
Pires-Zottarelli et al. (1996) e Pires-Zottarelli (1999) mencionam a existência de oogônios menores, citando, respectivamente, de 17,5-23,5 $\mu \mathrm{m}$ diâm. e 20-28 $\mu \mathrm{m}$ diâm. Concordam com a descrição de Gomes \& Pires-Zottarelli (2008), no entanto, estas citam apenas a presença de gotículas lipídicas subcêntricas nos oósporos.

Leptolegnia eccentrica Coker, J. Elisha Mitchell Sci. Soc. 42: 215. 1927.

Figura 10

Talo monóico. Micélio presente em ecdise de cobra. Zoosporângios cilíndricos, longos. Zoósporos dimórficos, dispostos em uma única fileira no zoosporângio; alongados durante a liberação, mas se tornando piriformes e nadando antes de encistar. Gemas ausentes. Oogônios laterais, esféricos, 16,5-24 $\mu \mathrm{m}$ diâm., parede oogonial com algumas papilas; pedúnculo simples. Anterídios presentes; ramos anteridiais andróginos, 1 por oogônio. Oósporos excêntricos, esféricos, 10,5-19,5 $\mu \mathrm{m}$ diâm., parede irregular ou enrugada; 1 por oogônio.

Material examinado: BRASIL. São PAULO: Parque Estadual da Serra da Cantareira, sapróbio em semente de sorgo, amostra de solo, 31-III-2006, M.L. Miranda s.n. (CCIBt2143).

A presença de papilas nos oogônios, sendo as mesmas variáveis em número, oósporos excêntricos e anterídios andróginos são características da espécie. As características do isolado estudado concordam com Gomes \& Pires-Zottarelli (2008). O espécime apresentou oogônios e oósporos menores, quando comparados com a descrição de Johnson et al. (2002), que citam, respectivamente, de 16-43 $\mu \mathrm{m}$ diâm. e 14-38 $\mu \mathrm{m}$ diâm.

Leptolegnia subterranea Coker \& J.V. Harv., J. Elisha Mitchell Sci. Soc. 41: 158. 1925.

Figuras 11-12

Talo monóico. Micélio limitado. Zoosporângios filiformes, longos. Zoósporos dimórficos, dispostos em uma única fileira no zoosporângio; alongados durante a liberação, mas se tornando piriformes e nadando antes de encistar. Gemas ausentes. Oogônios laterais, esféricos, 25-65 $\mu \mathrm{m}$ diâm.; parede oogonial com papilas de 2,5-15 $\mu \mathrm{m}$ compr. Anterídios ausentes. Oósporos subexcêntricos, esféricos; 1 por oogônio. 

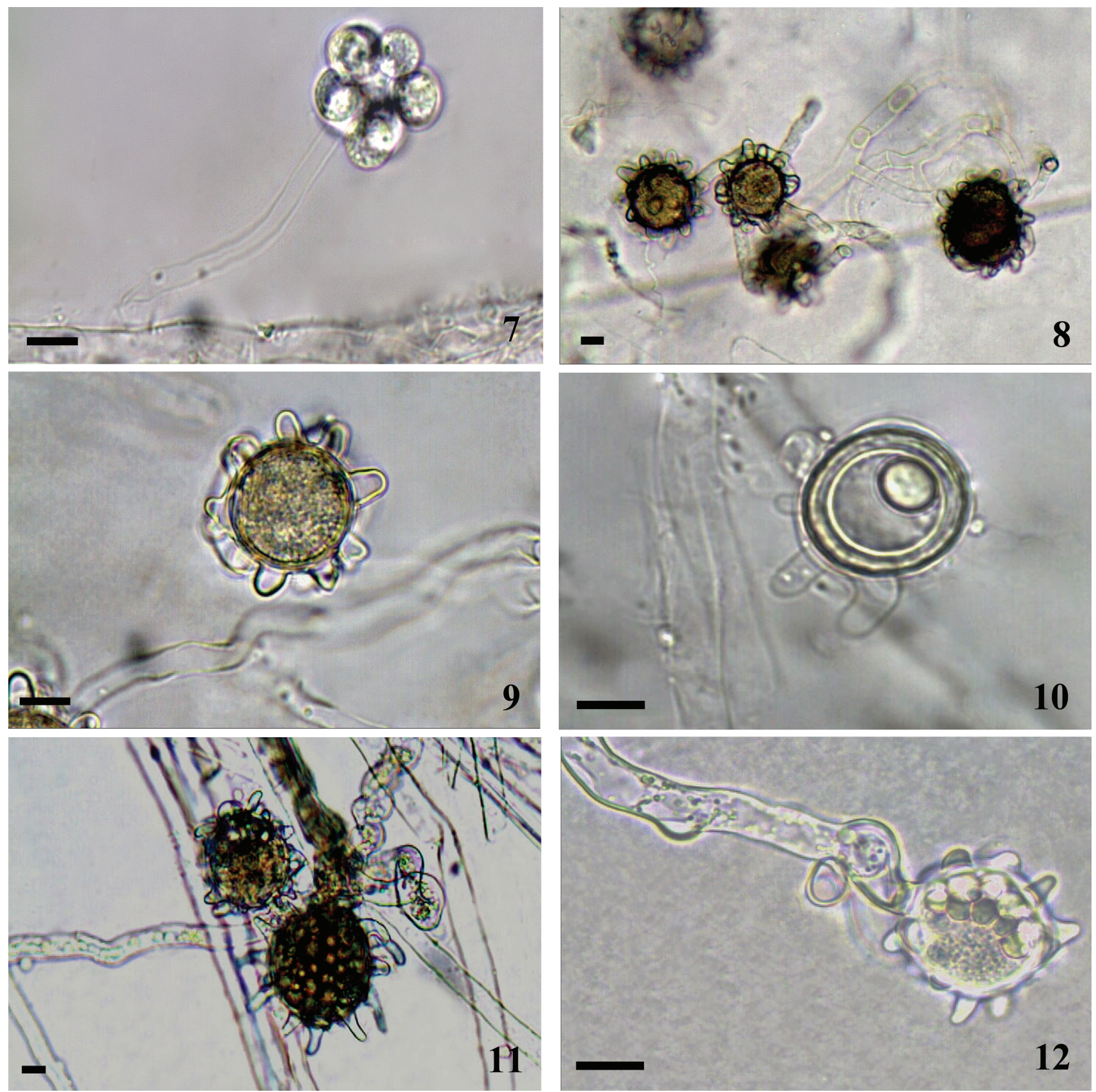

Figuras 7-12. Oomicetos do Parque Estadual da Serra da Cantareira. 7-9. Aphanomyces stellatus de Bary. 7. Liberação de zoósporos. 8. Aspecto geral do talo evidenciando oogônios ornamentados e anterídios. 9. Oogônio com ornamentações tuberculadas e oósporo cêntrico. 10. Leptolegnia eccentrica Coker \& Matthews. Oogônio papilado com oósporo excêntrico. 11-12. Leptolegnia subterranea Coker \& Harvey. 11. Oogônios ornamentados. 12. Oogônio com oósporo subexcêntrico. Barras $=10 \mu \mathrm{m}$.

Figures 7-12. Oomycetes from the Parque Estadual da Serra da Cantareira. 7-9. Aphanomyces stellatus de Bary. 7. Zoospores liberation. 8. Thallus with ornamented oogonia and antheridia. 8. Oogonium with tuberculate ornamentation and centric oospore. 10. Leptolegnia eccentrica Coker \& Matthews. Pappilate oogonium with eccentric oospore. 11-12. Leptolegnia subterranea Coker \& Harvey. 11. Ornamented oogonia. 12. Oogonium with subeccentric oospore. Bars $=10 \mu \mathrm{m}$. 
Material examinado: BRASIL. SÃo PaUlo: Parque Estadual da Serra da Cantareira, sapróbio em semente de sorgo, amostras de água e solo, 8-VI-2005, 21-IX-2005, M.L. Miranda s.n. (CCIBt2015).

A característica marcante da espécie é a presença de oogônios com papilas, oósporos subexcêntricos e ausência de anterídios. Os isolados apresentaram oogônios maiores que os descritos por Harvey (1925), Johnson et al. (2002) e Gomes \& Pires-Zottarelli (2006), que citam, respectivamente, de 40-51,7 $\mu \mathrm{m}$ diâm., 20-57 $\mu \mathrm{m}$ diâm. e 37,5-42,5 $\mu \mathrm{m}$ diâm., com as últimas relatando a ocorrência da espécie pela primeira vez para o país em área de Mata Atlântica da Reserva Biológica de Paranapiacaba, Santo André (SP).

Plectospira myriandra Drechsler, J. Agric. Res. 34: 294. 1927.

Figuras 13-14

Talo monóico. Micélio limitado. Zoosporângios lobulados formando complexos lobulares; 1 a 2 tubos para liberação dos zoósporos. Liberação dos zoósporos aclióide. Gemas ausentes. Oogônios laterais, esféricos, 22,5-32,5 $\mu \mathrm{m}$ diâm., às vezes ovais; amarelados; parede lisa; pedúnculo simples. Ramos anteridiais díclinos, raramente monóclinos; simples; célula anteridial simples; atracação lateral; tubo de fertilização não observado. Oósporos subcêntricos, esféricos, 17,5-22,5 $\mu \mathrm{m}$ diâm.; 1 por oogônio.

Material examinado: BRASIL. São PAulo: Parque Estadual da Serra da Cantareira, sapróbio em epiderme de cebola e semente de sorgo, amostras de água e solo, 8-VI-2005, 31-III-2006, 12-VI-2006, M.L. Miranda s.n. (CCIBt2117).

A presença de oogônios amarelados, oósporos subcêntricos e anterídios díclinos e monóclinos, são características marcantes da espécie. As características dos isolados concordam com Rocha (2002) e Drechsler (1927), porém, este último menciona a presença de oósporos excêntricos, embora ilustre subcêntricos, de 13-30 $\mu \mathrm{m}$ diâm. Os espécimes em estudo apresentaram oogônios maiores quando comparados ao isolado de Gomes et al. (2003), que citam de 20-27 $\mu \mathrm{m}$ diâm., as quais citam a espécie pela primeira vez para o país de área de cerrado da Reserva Biológica de Mogi Guaçu, Mogi Guaçu (SP).

\section{SAPROLEGNIACEAE}

Achlya apiculata de Bary, Bot. Ztg. 46: 635. 1888. Figuras 15-16
Talo monóico. Micélio limitado. Zoosporângios raros, filiformes, 300-580 × 30-50 $\mu \mathrm{m}$; liberação aclióide dos zoósporos. Gemas presentes. Oogônios laterais ou intercalares, esféricos, 47,5-90 $\mu \mathrm{m}$ diâm., piriformes, 82,5-87,5 × 67,5-70 $\mu \mathrm{m}$ ou ovais; parede lisa ou apiculada; pedúnculo simples, curvados ou pendentes, às vezes enrolados, raramente retos. Anterídios presentes; ramos anteridiais monóclinos, andróginos ou díclinos; atracação lateral, 1 a 3 por oogônio; tubo de fertilização presente. Oósporos frequentemente subcêntricos, raramente cêntricos; esféricos, 25-35 $\mu \mathrm{m}$ diâm., 1 a 14 por oogônio.

Material examinado: BRASIL. São Paulo: Parque Estadual da Serra da Cantareira, sapróbio em semente de sorgo, amostras de água e solo, 21-IX-2005, 31-III-2006, M.L. Miranda s.n. (SP381888).

As características principais da espécie são oogônios com oósporos subcêntricos e/ou cêntricos, alguns apiculados, com pedúnculos curvados, pendentes, alguns enrolados. Os zoosporângios e oogônios dos isolados se apresentaram menores, quando comparados com a descrição de Johnson et al. (2002), que citam, respectivamente, $140-700 \times 15-57 \mu \mathrm{m}$ e $(50-) 60-80(-140) \times(40-) 50-60(-110) \mu \mathrm{m}$. Gomes \& Pires-Zottarelli (2008) mencionam zoosporângios e oogônios menores, de 117,5-460 × 17,5-40 $\mu \mathrm{m}$ e 45-65 $\mu \mathrm{m}$ diâm., respectivamente.

Achlya caroliniana Coker, Bot. Gaz. 50: 381. 1910. Figuras 17-19

Talo monóico. Micélio limitado. Zoosporângios filiformes e/ou fusiformes, 150-680 × 20-40 $\mu \mathrm{m}$; renovação simpodial; liberação aclióide dos zoósporos. Gemas presentes. Oogônios laterais, esféricos, 25-37,5 $\mu \mathrm{m}$ diâm., piriformes, 30-50 × 25-40 $\mu \mathrm{m}$, frequentemente irregulares, raramente sésseis; parede lisa ou com projeções papiladas; pedúnculo simples. Anterídios presentes, raros; ramos anteridiais simples, normalmente monóclinos, ocasionalmente díclinos, raramente exíginos; células anteridiais simples ou divididas, atracação lateral; tubo de fertilização presente. Oósporos excêntricos, esféricos, 17,5-25 m diâm., alguns ovais, 1-4 por oogônio.

Material examinado: BRASIL. São Paulo: Parque Estadual da Serra da Cantareira, sapróbio em semente de sorgo, amostras de água e solo, 8-VI-2005, 21-IX-2005, 12-VI-2006, M.L. Miranda s.n. (CCIBt2009).

A rara presença de anterídios, oogônios com parede lisa, algumas vezes papilada e oósporos 

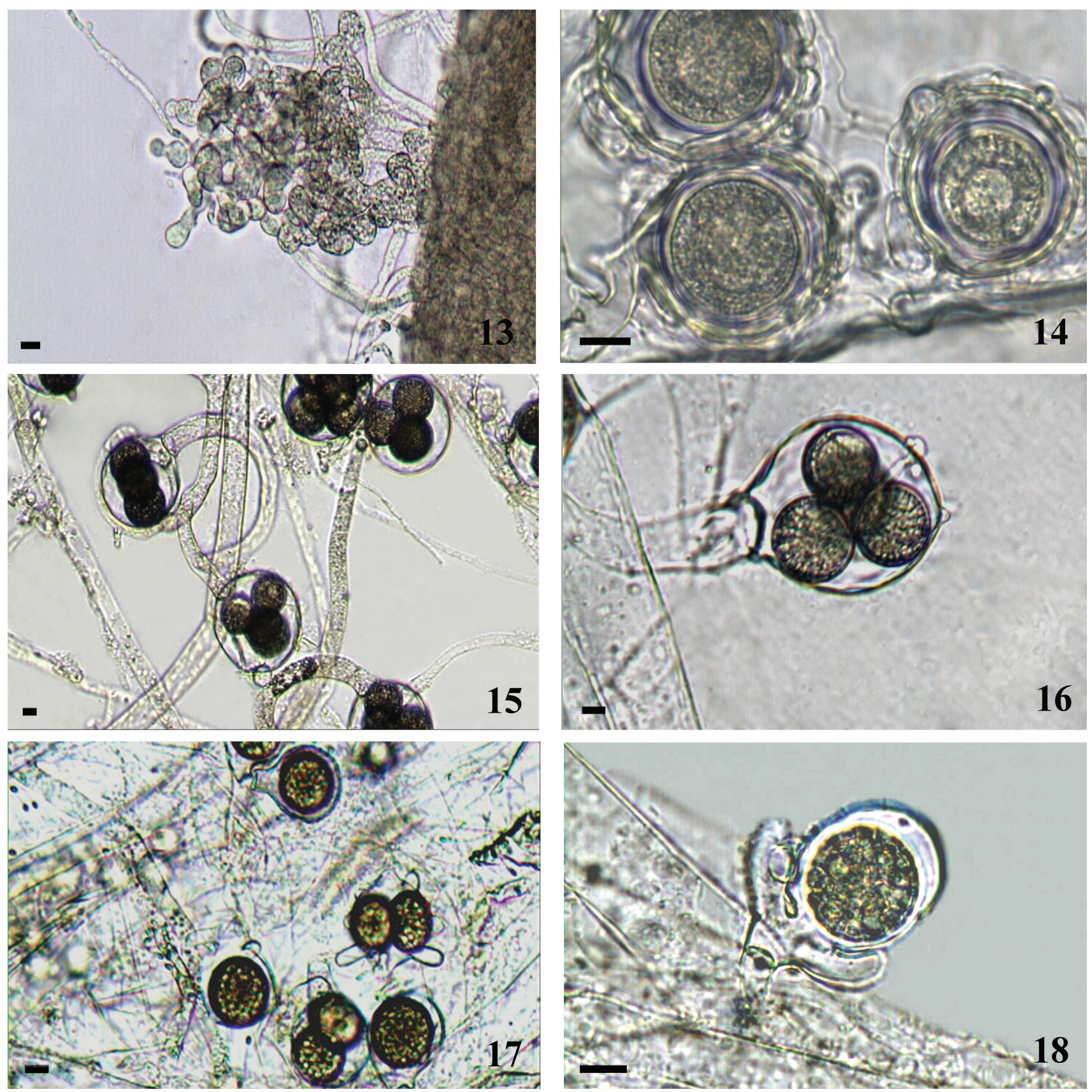

Figuras 13-18. Oomicetos do Parque Estadual da Serra da Cantareira. 13-14. Plectospira myriandra Drechsler. 13. Zoosporângios lobulados formando complexos. 14. Oogônios com oósporos subcêntricos e anterídios envolvendo os mesmos. 15-16. Achlya apiculata de Bary. 15. Aspecto geral dos oogônios no talo. 16. Oogônio apiculado com oósporos subcêntricos. 17-18. Achlya caroliniana Coker. 17. Oogônios lisos e papilados com oosferas. 18. Oogônio com oosfera e anterídio exígino. Barras $=10 \mu \mathrm{m}$.

Figures 13-18. Oomycetes from the Parque Estadual da Serra da Cantareira. 13-14. Plectospira myriandra Drechsler. 13. Lobulate zoosporangia in complex. 14. Oogonia with subcentric oospores and antheridia surrounding them. 15-16. Achlya apiculata de Bary. 15. Oogonia in the thallus. 16. Apiculate oogonium with subcentric oospores. 17-18. Achlya caroliniana Coker. 17. Smooth and pappilate oogonia with oospheres. 18. Oogonium with oospheres and exiginous antheridium. Bars $=10 \mu \mathrm{m}$. 
excêntricos são características marcantes da espécie. Foram observados zoosporângios maiores do que os descritos por Johnson (1956), que cita zoosporângios de 130-480 × 25-52 $\mu \mathrm{m}$, e oogônios menores, de 21-76 $\mu \mathrm{m}$ diâm. Os isolados estudados por Pires-Zottarelli et al. (1996) apresentaram zoosporângios menores, as quais citam de 180-480 × 26-50 $\mu \mathrm{m}$. Gomes et al. (2003) mencionam zoosporângios menores e oogônios esféricos maiores, $174-201 \times 23-40 \mu \mathrm{m}$ e 29-49 $\mu \mathrm{m}$ diâm., respectivamente.

Nos isolados estudados foi verificada a presença, embora rara, de anterídios exíginos, sendo esta a primeira citação deste tipo de anterídio na espécie.

Achlya flagellata Coker, The Saprolegniaceae with notes on other water moulds: 116. 1923.

Figuras 20-21

Talo monóico. Micélio limitado. Zoosporângios fusiformes, 240-670 × 20-50 $\mu \mathrm{m}$; renovação basipetalar; liberação aclióide dos zoósporos. Gemas presentes. Oogônios laterais, esféricos, 42,5-57,5 $\mu \mathrm{m}$ ou piriformes de 47,5-65 × 40-70 $\mu \mathrm{m}$; parede lisa, com poros no ponto de atracação dos anterídios; pedúnculo simples, algumas vezes pendentes. Anterídios presentes; ramos anteridiais díclinos, raramente monóclinos; célula anteridial simples ou dividida; atracação lateral ou apical por projeções; tubo de fertilização não observado. Oosferas normalmente abortivas. Oósporos excêntricos, esféricos, 22,5-30 ㅆm diâm.; 1-7 por oogônio.

Material examinado: BRASIL. São PAulo: Parque Estadual da Serra da Cantareira, sapróbio em semente de sorgo, amostras de água e solo, 8-VI-2005, 21-IX-2005, 13-XII-2005, 31-III-2006, 12-VI-2006, M.L. Miranda s.n. (CCIBt2008).

A espécie é caracterizada pela presença de muitos anterídios díclinos, oósporos excêntricos, no entanto, frequente presença de oosferas abortivas. As características dos espécimes isolados concordam com as descrições de Johnson (1956) e Gomes \& Pires-Zottarelli (2008).

Achlya klebsiana Pieters, Bot. Gaz. 60: 486. 1915. Figura 22

Talo monóico. Micélio limitado. Zoosporângios fusiformes, 75-237,5 × 12,5-35 $\mu \mathrm{m}$; renovação cimosa; liberação aclióide dos zoósporos. Gemas presentes. Oogônios laterais, esféricos, 45-87,5 ㅆm diâm., piriformes, $50-67,5 \times 40-57,5 \mu \mathrm{m}$; parede oogonial lisa; pedúnculo reto, simples. Anterídios presentes; ramos anteridiais díclinos, raramente monóclinos, saindo de um ponto distante do oogônio; pedúnculo simples; célula anteridial simples ou dividida; atracação lateral, apical ou por projeções; 1 a 7 por oogônio; tubo de fertilização presente. Oósporos excêntricos, esféricos 25-47,5 $\mu \mathrm{m}$ diâm., raramente oval; 1 a 16 por oogônio.

Material examinado: BRASIL. São Paulo: Parque Estadual da Serra da Cantareira, sapróbio em semente de sorgo, amostras de água e solo, 21-IX-2005, 13-XII-2005, 12-VI-2006, M.L. Miranda s.n. (CCIBtT2010).

A característica marcante da espécie é a presença de renovação cimosa dos zoosporângios, anterídios monóclinos com origem distante ao oogônio e oósporos excêntricos. Quando comparados com a descrição de Pires-Zottarelli et al. (1996), os espécimes apresentam zoosporângios menores e, oogônios e oósporos maiores, os quais citam, respectivamente, $224-431 \times 18-39 \mu \mathrm{m}, 31-45 \mu \mathrm{m}$ diâm. e 15-25 $\mu \mathrm{m}$ diâm. Os isolados observados por Gomes \& Pires-Zottarelli (2008) apresentam zoosporângios maiores e, oogônios e oósporos menores, as quais citam respectivamente, $330-650 \times 30-50 \mu \mathrm{m}$; 27,5-65 $\mu \mathrm{m}$ diâm. e 17,5-30 $\mu \mathrm{m}$ diâm.

Achlya orion Coker \& Couch, J. Elisha Mitchell Sci Soc. 36: 100. 1920.

Figura 23

Talo monóico. Micélio limitado. Zoosporângios filiformes, $140-420 \times 20-50 \mu \mathrm{m}$; renovação simpodial; liberação aclióide dos zoósporos. Gemas presentes. Oogônios laterais, esféricos, 37,5-62,5 $\mu \mathrm{m}$ diâm. ou piriformes, 37,5-62,5 × 42,5-47,5 $\mu \mathrm{m}$; parede lisa; pedúnculo simples, curvados e/ou retorcidos, raramente retos. Anterídios presentes; ramos anteridiais andróginos, monoclinos, raramente díclinos, simples; células anteridiais simples ou divididas, atracação lateral, 1-4 por oogônio; tubo de fertilização presente. Oosferas maturando. Oósporos excêntricos, esféricos, 22,5-30 بm diâm., alguns ovais; 1-6 por oogônio.

Material examinado: BRASIL. São PAUlo: Parque Estadual da Serra da Cantareira, sapróbio em semente de sorgo, amostras de água e solo, 8-VI-2005, 21-IX-2005, 13-XII-2005, 31-III-2006, M.L. Miranda s.n. (SP381889).

A frequente presença de oogônios com pedúnculos curvos e/ou retorcidos e oósporos excêntricos 

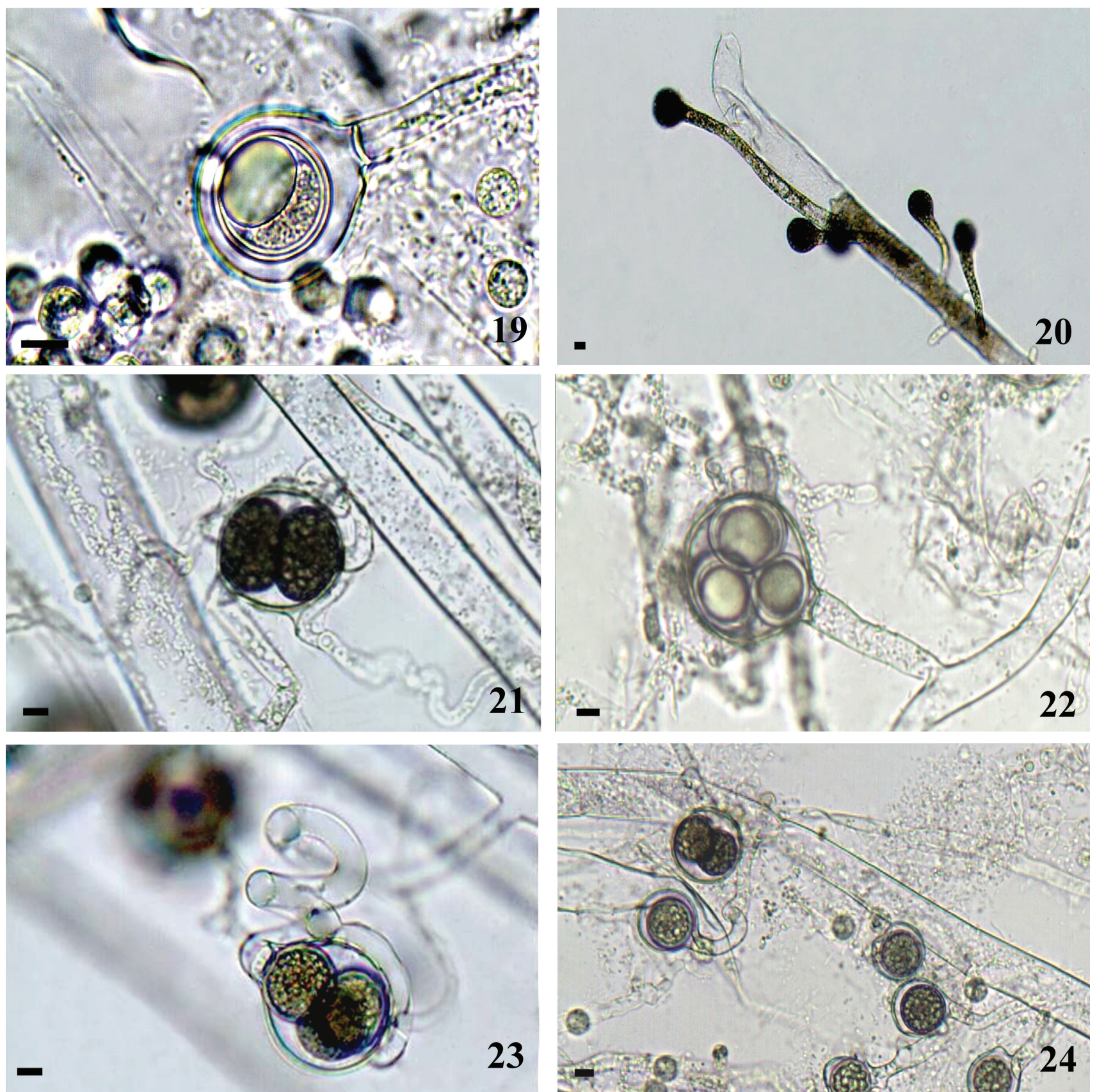

Figuras 19-24. Oomicetos do Parque Estadual da Serra da Cantareira. 19. Achlya caroliniana Coker. Oogônio com oósporo excêntrico. 20-21. Achlya flagellata Coker. 20. Talo evidenciado zoosporângio vazio e oogônios em formação. 21. Oogônio com oosferas e anterídios díclinos. 22. Achlya klebsiana Pieters. Oogônio com oósporos excêntricos e anterídios díclinos. 23. Achlya orion Coker \& Couch. Oogônio com oosferas e pedúnculo retorcido. 24. Achlya oviparvula Rogers \& Beneke. Aspecto geral do talo com oogônios e oosferas em processo de maturação. Barras $=10 \mu \mathrm{m}$ para as figuras 19, 21, 22, 23 e 24. Barras $=20 \mu \mathrm{m}$ para a figura 20.

Figures 19-24. Oomycetes from the Parque Estadual da Serra da Cantareira. 19. Achlya caroliniana Coker. Oogonium with eccentric oospores. 20-21. Achlya flagellata Coker. 20. Empty zoosporangium and oogonia in formation. 21. Oogonium with oospheres and diclinous antheridia. 22. Achlya klebsiana Pieters. Oogonium with eccentric oospores and diclinous antheridia. 23. Achlya orion Coker \& Couch. Oogonium with oospheres and twisted stalk. 24. Achlya oviparvula Rogers \& Beneke. Thallus with oogonia and oospheres in maturation. Bars $=10 \mu \mathrm{m}$ to the figures 19, 21, 22, 23 and 24. Bars $=20 \mu \mathrm{m}$ to the figure 20. 
são características marcantes dessa espécie. As características dos isolados estudados concordam com a descrição de Milanez (1970) e Pires-Zottarelli (1999). Johnson et al. (2002) menciona zoosporângios maiores de 45-700 × 17-52 $\mu \mathrm{m}$. Comparando os espécimes com a descrição de Gomes \& Pires-Zottarelli (2008), apresentaram oogônios esféricos maiores, as quais citam de 35-47,5 $\mu$ m diâm.

Achlya oviparvula A.L. Rogers \& Beneke, Rickia 1: 244. 1962.

Figura 24

Talo monóico. Micélio limitado. Zoosporângios filiformes, 190-580 × 10-70 $\mu \mathrm{m}$; renovação simpodial, basipetalar ou cimosa; presença de poros laterais nos zoosporângios; liberação aclióide dos zoósporos. Gemas presentes. Oogônios esféricos, 20-25 بm diâm., piriformes, $22,5-30 \times 17,5-20 \mu \mathrm{m}$., irregulares ou ovais; parede lisa, algumas vezes com papilas de 5-10 $\mu \mathrm{m}$ de compr.; pedúnculo simples, reto. Anterídios ausentes. Oósporos excêntricos, esféricos; 1 a 2 por oogônio, normalmente 1 .

Material examinado: BRASIL. São PAulo: Parque Estadual da Serra da Cantareira, sapróbio em semente de sorgo, amostras de água e solo, 8-VI-2005, 21-IX-2005, 12-VI-2006, M.L. Miranda s.n. (CCIBt2017).

A característica marcante da espécie é a ausência de anterídios e a presença de oósporos excêntricos. Os espécimes observados concordam com a descrição de Rogers \& Beneke (1962) e Pires-Zottarelli et al. (1996). Johnson et al. (2002) citam a rara presença de anterídios, mas, até o momento, nenhum dos isolados brasileiros (Beneke \& Rogers, 1970; Pires-Zottarell et al. 1996, Rocha \& Pires-Zottarelli, 2002) apresentaram tal estrutura, concordando com a descrição original.

Achlya prolifera C.G. Nees, Nova Acta Phys.-Med. Acad, Caes. Leop.-Carol.Nat. Cur.: 11: 514. 1823. Figuras 25-26

Talo monóico. Micélio limitado. Zoosporângios filiformes, $130-420 \times 10-30 \mu \mathrm{m}$; renovação simpodial; liberação aclióide dos zoósporos. Gemas presentes. Oogônios laterais, esféricos, 37,5-67,5 $\mu \mathrm{m}$ diâm., piriformes; parede lisa; pedúnculo simples. Anterídios presentes; ramos anteridiais díclinos envolvendo os pedúnculos oogoniais e os oogônios; atracação apical ou lateral; tubo de fertilização não observado.
Oósporos excêntricos, esféricos, 17,5-25 ㅆm diâm., 3 a 5 por oogônio.

Material examinado: BRASIL. São PAUlo: Parque Estadual da Serra da Cantareira, sapróbio em semente de sorgo, amostras de água e solo, 8-VI-2005, 21-IX-2005, 12-VI-2006, M.L. Miranda s.n. (CCIBt2025).

A característica marcante da espécie é a presença de ramos anteridiais envolvendo os pedúnculos oogoniais e os oogônios, e a presença de oósporos excêntricos. Johnson et al. (2002) citam, em sua monografia, zoosporângios e oogônios maiores, de

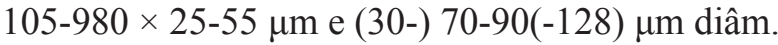

Achlya radiosa Maurizio, Mitt. Deutsch. FischereiVereins 7: 57. 1899.

Figura 27

Talo monóico. Micélio limitado. Zoosporângios filiformes ou fusiformes, $180-320 \times 20-30 \mu \mathrm{m}$ diâm.; renovação simpodial; liberação aclióide dos zoósporos. Gemas presentes. Oogônios laterais, esféricos 40-57,5 $\mu \mathrm{m}$ diâm., raramente piriforme; parede oogonial com ornamentações mamiformes ou duplo mamiformes, 7,5-17,5 × 5-15 $\mu \mathrm{m}$; pedúnculo simples. Anterídios presentes; ramos anteridiais andróginos, simples; 1 a 2 por oogônio; tubo de fertilização não observado. Oosferas maturando. Oósporos subcêntricos, esféricos, 20-30 $\mu \mathrm{m}$ diâm.; 1 por oogônio.

Material examinado: BRASIL. São Paulo: Parque Estadual da Serra da Cantareira, sapróbios em semente de sorgo, amostras de água e solo, 8-VI-2005, 21-IX-2005, 13-XII-2005, 31-III-2006, 12-VI-2006, M.L. Miranda s.n. (CCIBt2014).

A característica marcante da espécie é a presença de oogônios com ornamentações mamiformes e duplo-mamiformes, oósporos subcêntricos e anterídios andróginos. Foi descrita como Achlya pseudoradiosa por Beneke \& Rogers (1962), e colocada em sinonímia com Achlya radiosa por Johnson et al. (1975), pelo tipo das ornamentações oogoniais apresentadas. As características dos espécimes concordam com Gomes \& Pires-Zottarelli (2008), entretanto as autoras citam zoosporângios maiores, de 237,5-500 × 20-30 $\mu \mathrm{m}$.

Dictyuchus pseudodictyon Coker \& Braxton, J. Elisha Mitchell Sci. Soc., 46: 228. 1931.

Figuras 28-30

Talo monóico. Micélio limitado. Zoosporângios fusiformes, $150-460 \times 20-30 \mu \mathrm{m}$, frequentemente 

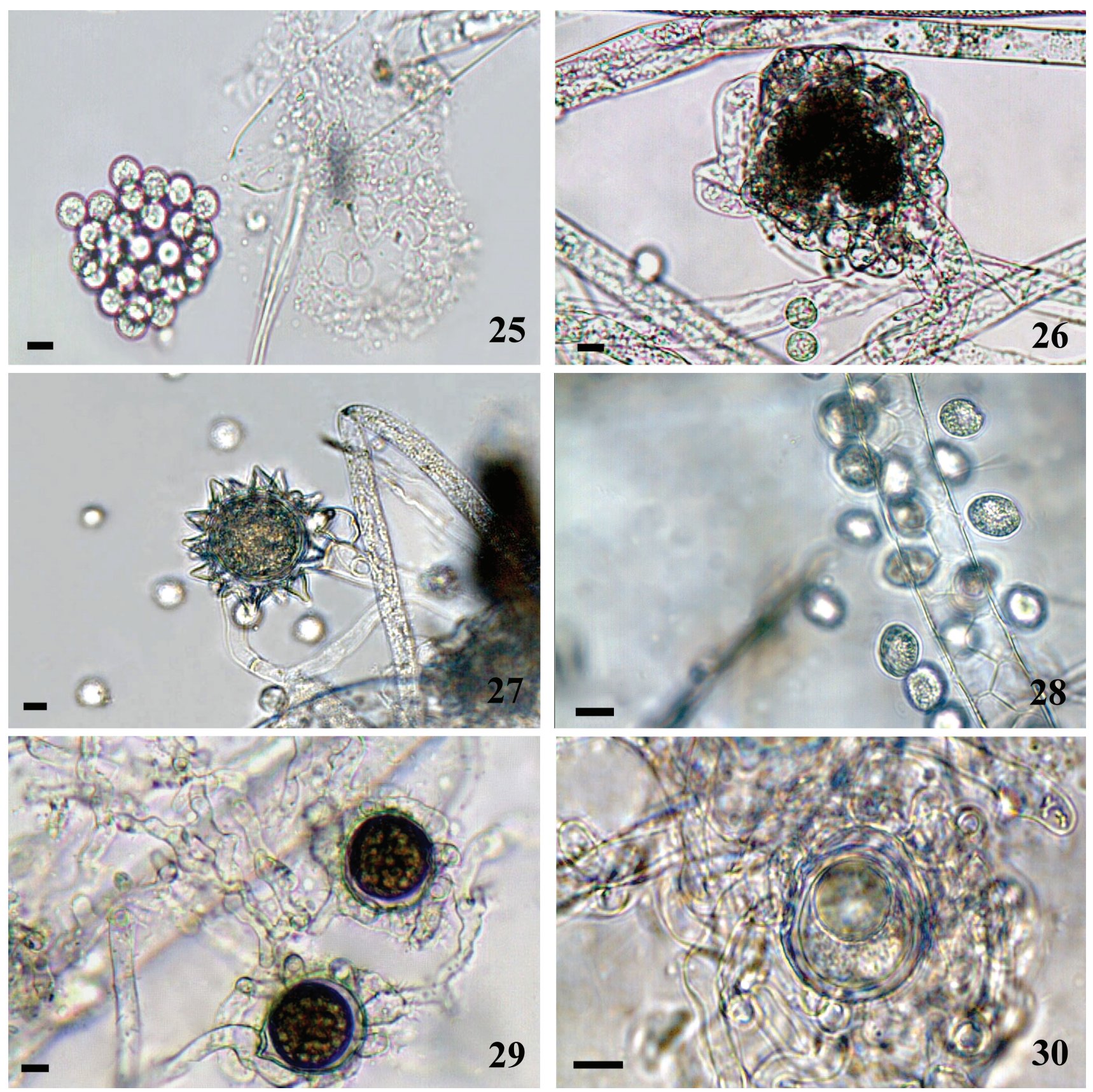

Figuras 25-30. Oomicetos do Parque Estadual da Serra da Cantareira. 25-26. Achlya prolifera C.G. Nees. 25. Zoosporângio com liberação aclióide. 26. Oogônio com anterídios enrolando no pedúnculo oogonial e oogônio. 27. Achlya radiosa Maurizio. Oogônio ornamentado com anterídios andróginos. 28-30. 28. Dictyuchus pseudodictyon Coker \& Braxton ex Couch. 28. Zoosporângio com liberação dictióide. 29. Oogônios com oosferas e anterídios. 30. Oogônio com oósporo excêntrico e anterídios. Barras $=10 \mu \mathrm{m}$.

Figures 25-30. Oomycetes from the Parque Estadual da Serra da Cantareira. 25-26. Achlya prolifera C.G. Nees. 25. Achlyoid liberation of the zoosporangium. 26. Oogonium and surrounding antheridia in the oogonial stalk and oogonium. 27. Achlya radiosa Maurizio. Ornamented oogonium with androgynous antheridia. 28-30. 28. Dictyuchus pseudodictyon Coker \& Braxton ex Couch. 28. Dictyoid liberation of the zoosporangium. 29. Oogonia with oospheres and antheridia. 30. Oogonium with eccentric oospore and antheridia. Bars $=10 \mu \mathrm{m}$. 
decíduos; renovação simpodial. Zoósporos encistados dentro do zoosporângio, a seguir, emergindo na forma biflagelada e deixando os seus cistos na forma de uma rede; rede falsa e verdadeira presentes. Gemas ausentes. Oogônios laterais, terminais, esféricos, 24-36 $\mu \mathrm{m}$ diâm., piriformes, 25,5-27 × 22,5-24 $\mu \mathrm{m}$; parede lisa; pedúnculo simples. Anterídios presentes; ramos anteridiais díclinos, envolvendo os oogônios, simples; atracação lateral, apical; célula anteridial simples; tubo de fertilização não observado. Oósporos excêntricos, esféricos, 12,5-20 $\mu \mathrm{m}$ diâm.; 1 por oogônio.

Material examinado: BRASIL. São Paulo: Parque Estadual da Serra da Cantareira, sapróbio em semente de sorgo, amostras de água e solo, 8-VI-2005, 21-IX-2005, 13-XII-2005, 31-III-2006, 12-VI-2006, M.L. Miranda s.n. (CCIBt2018).

A presença de cistos deixados dentro dos zoosporângios pelos zoósporos, formando rede verdadeira e falsa, anterídios díclinos envolvendo o oogônio e oósporos excêntricos são características marcantes da espécie. As características dos isolados estudados estão de acordo com Johnson et al. (2002), no entanto, os autores citam zoosporângios e oósporos

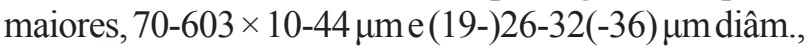
respectivamente. Apresentaram oósporos menores quando comparados a Gomes \& Pires-Zottarelli (2008), as quais citam de 20-35 $\mu \mathrm{m}$ diâm.

Phragmosporangium uniseriatum R.L. Seym., Mycotaxon 92: 8. 2005.

Figuras 31-33

Talo monóico. Micélio delicado, limitado. Zoosporângios filiformes, longos, ramificados, com 1 a 2 fileiras de zoósporos, normalmente 1 . Descarga de zoósporos dictióide. Gemas ausentes. Oogônios laterais, raramente terminais, esféricos, 20-30 $\mu \mathrm{m}$ diâm., ocasionalmente irregulares; amarelados; parede lisa, irregulares, algumas vezes papiladas; pedúnculo simples. Anterídios presentes; ramos anteridiais monóclinos, andróginos e raramente díclinos, simples, célula anteridial simples; atracação apical e lateral; 1 a 3 por oogônio. Oosferas maturando. Oósporos subcêntricos, alguns cêntricos, amarelados, esféricos, 12,5-20 $\mu \mathrm{m}$ diâm., 1 por oogônio.

Material examinado: BRASIL. São Paulo: Parque Estadual da Serra da Cantareira, sapróbio em semente de sorgo, amostras de água e solo, 8-VI-2005, 21-IX-2005, 13-XII-2005, 31-III-2006, 12-VI-2006, M.L. Miranda s.n. (CCIBtT2124).
Os espécimes isolados diferem daquele descrito por Johnson et al. (2005), devido a presença de zoósporos dispostos em duas fileiras, embora rara, dentro do zoosporângio, enquanto estes mencionam apenas uma fileira; oósporos cêntricos além de subcêntricos, parede externa dos oogônios não só irregular, mas também lisa ou papilada, como também oósporos menores, os quais citam de (19-)24-28(-32) $\mu \mathrm{m}$ diâm., além da coloração amarelada dos oogônios e oósporos. Concordam com as características dos espécimes estudados por Pires-Zottarelli et al. (2007), as quais relataram a ocorrência da espécie pela primeira vez para o país, com a citação de isolados de diversas áreas de Mata Atlântica.

Pythiopsis humphreyana Coker, Mycologia 6: 292. 1914.

Figuras 34-36

Talo monóico. Micélio limitado. Zoosporângios irregulares, ovais, 42,5-62,5 × 30-42,5 $\mu \mathrm{m}$, clavados, esféricos, 32,5-40 $\mu \mathrm{m}$ diâm.; parede lisa. Zoósporos monomórficos, somente do tipo primário, emergindo dos poros e nadando imediatamente. Gemas presentes. Oogônios intercalares, raramente laterais, esféricos, 22,5-40 $\mu \mathrm{m}$ diâm., piriformes, irregulares; pedúnculo simples; parede lisa, raramente apiculada. Anterídios presentes; ramos anteridiais andróginos, raramente díclinos; simples; atracação lateral ou apical; célula anteridial simples, clavada; tubo de fertilização presente; 1 por oogônio. Oósporos subcêntricos, raramente cêntricos, esféricos, 25-40 $\mu \mathrm{m}$ diâm.; 1 por oogônio.

Material examinado: BRASIL. São Paulo: Parque Estadual da Serra da Cantareira, sapróbio em semente de sorgo, amostras de água e solo, 8-VI-2005, 21-IX-2005, 13-XII-2005, 12-VI-2006, M.L. Miranda s.n. (CCIBt2012).

Anterídios andróginos e oósporos subcêntricos são características marcantes da espécie. As características dos espécimes estudados estão de acordo com Johnson et al. (2005), no entanto, os autores mencionam a presença de zoosporângios maiores, de 60-308 × 17-81 $\mu \mathrm{m}$. Os espécimes apresentaram zoosporângios esféricos e irregulares menores, quando comparados com a descrição de Gomes \& Pires-Zottarelli (2008), que mencionam de 32,5-47,5 $\mu \mathrm{m}$ diâm. e, 35-112,5 × 17,5-40 $\mu \mathrm{m}$, e oósporos maiores, as quais citam de 22,5-27 $\mu \mathrm{m}$ diâm. 

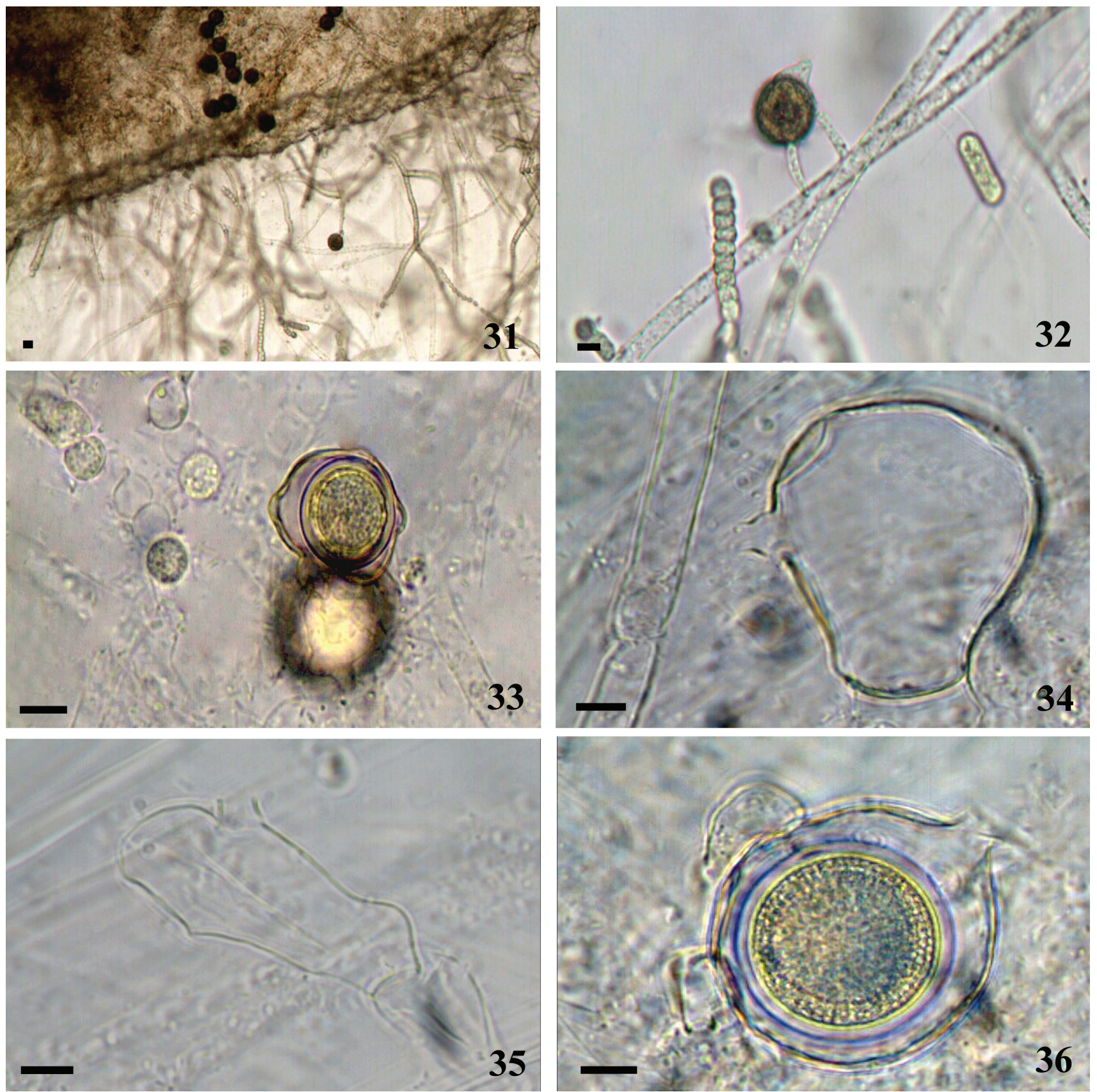

Figuras 31-36. Oomicetos do Parque Estadual da Serra da Cantareira. 31-33. Phragmosporangium uniseriatum Seym. 31. Aspecto geral do talo em ecdise de cobra. 32. Talo evidenciado parte de um zoosporângio com uma cadeia de esporos, oogônio em formação com anterídio monóclino. 33. Oogônio papilado com oósporo subcêntrico. 34-36. Pythiopsis humphreyana Coker. 34-35. Zoosporângios. 36. Oogônio com oósporo subcêntrico e células anteridiais atracando no oogônio. Barras $=10 \mu \mathrm{m}$ para as figuras 32,33 , 34,35 e 36 . Barras $=20 \mu \mathrm{m}$ para a figura 31 .

Figures 31-36. Oomycetes from the Parque Estadual da Serra da Cantareira. 31-33. Phragmosporangium uniseriatum Seym. 31. Thallus in the snake skin. 32. Thallus showing part of the one zoosporangium, oogonium in formation and monoclinous antheridium. 33. Pappilate oogonium with subcentric oospore. 34-36. Pythiopsis humphreyana Coker. 34-35. Zoosporangia. 36. Oogonium with subcentric oospore and antheridial cells in the oogonium. Bars $=10 \mu \mathrm{m}$ to the figures $32,33,34,35$ and 36 . Bars $=20 \mu \mathrm{m}$ to the figure 31 . 
Saprolegnia diclina Humphrey, Trans. Am. Phil. Soc. 17: 109. 1893.

Figuras 37-38

Talo monóico. Micélio limitado. Zoosporângios filiformes, $120-370 \times 20-50 \mu \mathrm{m}$, alguns clavados; proliferação interna presente. Liberação dos zoósporos saprolegnióide. Gemas presentes. Oogônios abundantes, laterais ou intercalares, esféricos, 42,5-67,5 m diâm., ocasionalmente piriformes, $50-100 \times 42,5-45 \mu \mathrm{m}$, catenulados ou sésseis; parede lisa; pedúnculo simples. Anterídios presentes; ramos anteridiais díclinos; células anteridiais simples ou divididas; 1 a 8 por oogônio; atracação lateral ou apical. Oosferas maturando. Oósporos subcêntricos, raramente cêntricos, esféricos, 25-30 $\mu \mathrm{m}$ diâm., 2-8 por oogônio.

Material examinado: BRASIL. São PAulo: Parque Estadual da Serra da Cantareira, sapróbio em semente de sorgo, amostra de água, 8-VI-2005, M.L. Miranda s.n. (CCIBt2016).

A característica principal da espécie é a presença de anterídios díclinos e oósporos subcêntricos a raramente cêntricos. As características do espécime estudado concordam com a descrição de Seymour (1970) e Pires-Zottarelli et al. (1996).

Saprolegnia parasitica Coker, The Saprolegniaceae with notes on other water molds: 30. 1923 . Figura 39

Talo monóico. Micélio limitado. Zoosporângios filiformes, $210-450 \times 22,5-40 \mu \mathrm{m}$, alguns clavados; proliferação interna presente. Liberação dos zoósporos saprolegnióide. Gemas presentes. Oogônios laterais, intercalares, esféricos, 47,5-77,5 $\mu \mathrm{m}$ diâm., piriformes, 70-135 × 55-82,5 $\mu \mathrm{m}$; parede lisa; pedúnculo simples. Anterídios presentes; ramos anteridiais díclinos; 1 a 6 por oogônio. Oósporos subcêntricos, esféricos, 22,5-30 $\mu \mathrm{m}$ diâm., ou raramente ovais; 1 a 28 por oogônio.

Material examinado: BRASIL. São Paulo: Parque Estadual da Serra da Cantareira, sapróbio em semente de sorgo, amostra de água, 8-VI-2005, M.L. Miranda s.n. (CCIBt2023).

As características principais da espécie são a presença de parede oogonial delgada, ramos anteridiais díclinos e oósporos subcêntricos. Seymour (1970) menciona que Saprolegnia parasitica e Saprolegnia diclina são espécies distintas, porém
Johnson et al. (2002) acreditam que ambas são sinonímias, uma vez que modificam suas estruturas de acordo com o ambiente em que se encontram. Diégues-Uribeondo et al. (2007), por meio de estudos morfológicos e moleculares, corroboram a opinião de Seymour (1970), propondo a continuidade da separação das duas espécies.

Thraustotheca clavata (de Bary) Humphrey, Trans. Am. Phil. Soc. II. 17:131. 1893.

Figuras 40-42

Talo monóico. Micélio limitado. Zoosporângios clavados, curtos, $60-170 \times 40-50 \mu \mathrm{m}$; renovação simpodial. Liberação dos zoósporos traustotecóide. Gemas raras. Oogônios laterais, esféricos, 32,5-55 $\mu$ m diâm., ou piriformes, 37,5-50 ×32,5-45 $\mu$ m; parede lisa; pedúnculo simples. Anterídios presentes; ramos anteridiais díclinos, simples; células anteridiais simples ou divididas; atracação lateral, apical ou por projeções; tubo de fertilização ausente. Oosferas maturando. Oósporos excêntricos, esféricos 20-22,5 $\mu \mathrm{m}$ diâm.; 1 a 6 por oogônio.

Material examinado: BRASIL. São Paulo: Parque Estadual da Serra da Cantareira, sapróbio em semente de sorgo, amostras de água e solo, 8-VI-2005, 21-IX-2005, 12-VI-2006, M.L. Miranda s.n. (CCIBt2011).

Zoosporângios clavados, anterídios díclinos e oósporos excêntricos, são as características da espécie. Os espécimes apresentaram zoosporângios menores quando comparados aos descritos por Johnson et al. (2002), os quais citam de 53-421 × 30-106 $\mu \mathrm{m}$.

Durante o período de estudo, Aphanomyces helicoides, Achlya flagellata, A. radiosa, Dictyuchus pseudodictyon e Phragmosporangium uniseriatum foram as espécies com a maior frequência (100\%), totalizando 90 ocorrências, das 179 observadas nas cinco coletas realizadas. Estes resultados evidenciam o caráter esporádico de ocorrência da maioria das espécies encontradas, demonstrando assim, a necessidade de esforço amostral para o levantamento do grupo. Dos táxons identificados, todos são primeira ocorrência para o Parque Estadual da Serra da Cantareira, no entanto, estes resultados não esgotam o conhecimento da diversidade do grupo no Parque, visto a abrangência do mesmo, mas ampliam o conhecimento da ocorrência e distribuição dos oomicetos em áreas de Mata Atlântica do Estado de São Paulo e do país. 

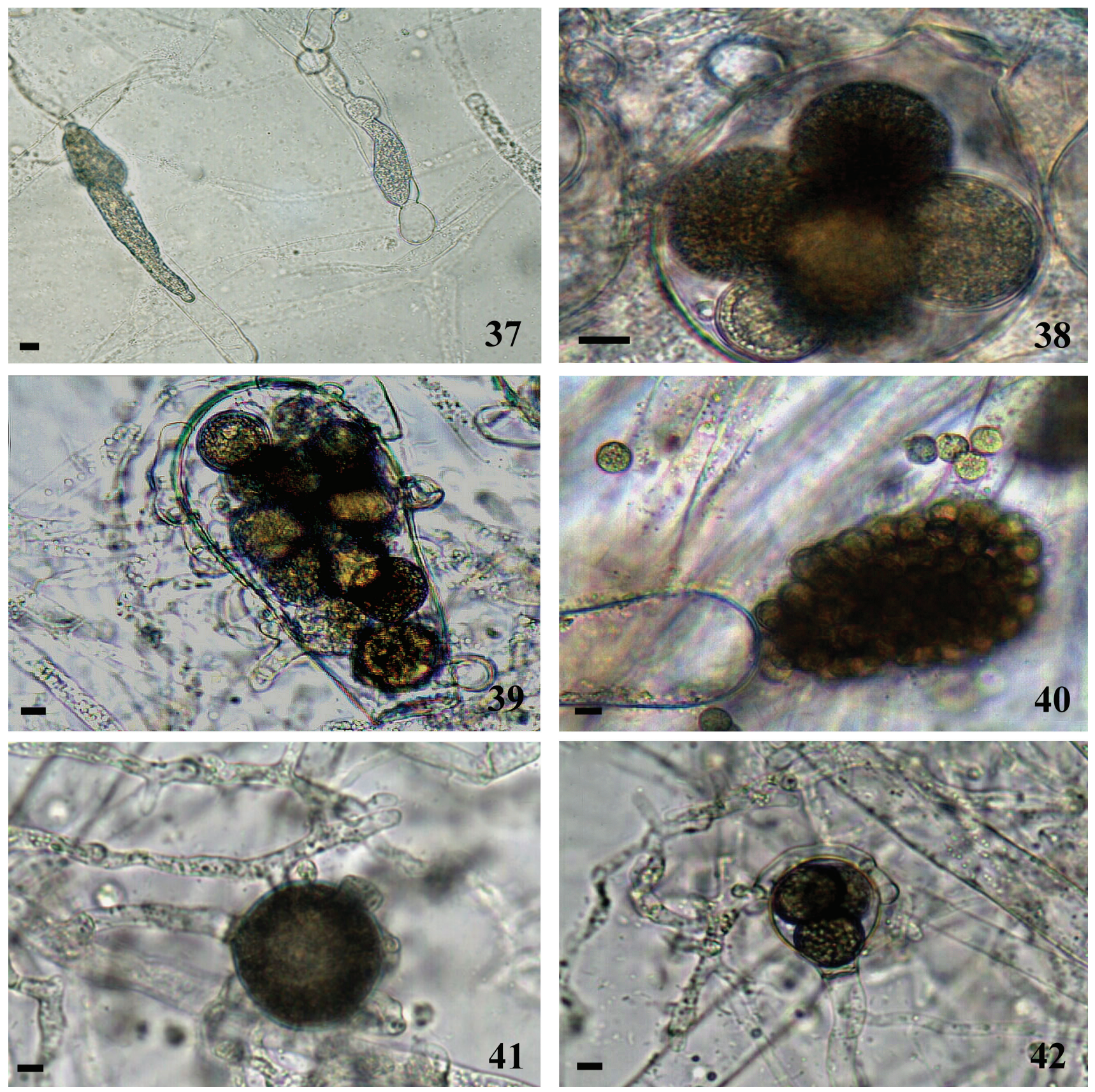

Figuras 37-42. Oomicetos do Parque Estadual da Serra da Cantareira. 37-38. Saprolegnia diclina Humphrey. 37. Zoosporângio com proliferação interna. 38. Oogônio com oosferas e oósporo subcêntrico. 39. Saprolegnia parasitica Coker. Oogônio com oosferas, oósporos e anterídios. 40-42. Thraustotheca clavata de Bary. 40. Zoosporângio clavado. 41. Oogônio em formação com ramos anteridiais díclinos. 42. Oogônio com oosferas e anterídio díclino. Barras $=10 \mu \mathrm{m}$.

Figures 37-42. Oomycetes from the Parque Estadual da Serra da Cantareira. 37-38. Saprolegnia diclina Humphrey. 37. Zoosporangium with internal proliferation. 38. Oogonium with oospheres and subcentric oospore. 39. Saprolegnia parasitica Coker. Oogonium with oospheres, oospores and antheridia. 40-42. Thraustotheca clavata de Bary. 40. Clavate zoosporangium. 41. Oogonium with oospheres and diclinous antheridium. 42. Oogonium with oospheres and antheridia. Bars $=10 \mu \mathrm{m}$. 


\section{Agradecimentos}

Ao Instituto Florestal, pela autorização concedida para a realização das coletas e suporte durante as mesmas, e ao CNPq pelo auxílio financeiro na forma de bolsa de produtividade para a segunda autora.

\section{Literatura citada}

Alexopoulos, C.J., Mims, C.W. \& Blackwell, M. 1996. Introductory Mycology. 4 ed. John Wiley, Sons, New York.

Beneke, E.S. \& Rogers, L. 1962. Aquatic Phycomycetes isolated in the states of Minas Gerais, São Paulo and Paraná, Brazil. Rickia 1: 181-193.

Beneke, E.S. \& Rogers, L. 1970. Aquatic fungi of Parque Nacional do Itatiaia in the state of Rio de Janeiro. Rickia 5: 51-64.

Diégues-Uribeondo, J., Fregeneda-Grandes, J.M., Cereneius, L., Pérez-Niesta, E., Aller-Gancedo, J.M., Tellería, M.T., Soderhall, K. \& Martín, M.P. 2007. Re-evaluation of the enigmatic species complex Saprolegnia diclina-Saprolegnia parasitica based on morphological, physiological and molecular data. Fungal Genetics and Biology 44: 585-601.

Drechsler, C. 1927. Two water molds causing tomato rootlet injury. Journal of the Agricultural Research 34: 294.

Figueiredo, M.B. \& Pimentel, C.P.V. 1975. Métodos utilizados para conservação de fungos na Micoteca da Seção de Micologia Fitopatológica do Instituto Biológico. Summa Phytopathologica 1: 299-302.

Furtado, J.S. 1965. A new aquatic fungus, Achlya benekei sp. nov. Rickia 2: 121-127.

Gomes, A.L. \& Pires-Zottarelli, C.L.A. 2006. Diversidade de Oomycota da Reserva Biológica de Paranapiacaba, Santo André, SP: primeiras citações para o Brasil. Revista Brasileira de Botânica 29: 569-577.

Gomes, A. L. \& Pires-Zottarelli, C.L.A. 2008. Oomycota (Straminipila) da Reserva Biológica de Paranapiacaba, Santo André, SP, Brasil. Acta Botanica Brasilica 22: 373-392.

Gomes, A.L., Pires-Zottarelli, C.L.A., Rocha, M. \& Milanez, A.I. 2003. Saprolegniaceae de áreas de cerrado do Estado de São Paulo, SP. Hoehnea 30: 95-110.

Harvey, J.V. 1925. A study of the water molds and Pythiums occurring in the soils of Chapel Hill. Journal of the Elisha Mitchell Scientific Society 41: 158.

Huneycutt, M.B. 1952. A new water mold on keratinized materials. Journal of the Elisha Mitchell Scientific Society 68: 109-112.

Johnson Jr., T.W. 1956. The genus Achlya: morphology and taxonomy. University of Michigan Press, Ann Arbor.
Johnson Jr., T.W., Rogers, AL. \& Beneke, E.S. 1975. Aquatic fungi of Iceland: comparative morphology of Achlya radiosa, Achlya pseudoradiosa and Achlya stellata. Mycologia 67: 108-119.

Johnson Jr., T.W., Seymour, R.L. \& Padgett, D.E. 2002. Biology and systematics of Saprolegniaceae. http://www.uncw.edu/people/padgett/book (acesso em 11.2002).

Johnson Jr., T.W., Seymour, R.L. \& Padgett, D.E. 2005. Systematics of the Saprolegniaceae: New taxa. Mycotaxon 92: 1-10.

Karling, JS. 1987. Two new species of Leptolegniella and other zoosporic fungi in Thailand soils. Nova Hedwigia 45: 433-443.

Kirk, P.M., Cannon, P.F., Minter D.W. \& Stalpers, J.A. 2008. Dictionary of fungi. 10 ed. CABI Publishing, Wallingford.

Lyra, N.P. \& Milanez, A.I. 1974. Notas para o levantamento dos ficomicetos aquáticos do estado de São Paulo. Publicação do Instituto de Micologia da Universidade Federal de Pernambuco, Recife 608: 1-27.

Milanez, A.I. 1970. Contributions to the knowledge of aquatic Phycomycetes of São Paulo state. I. Oomycetes form the west region. Rickia 5: 23-43.

Milanez, A.I. 1989. Fungos de águas continentais. In: O. Fidalgo \& V.L. Bononi (coords.). Técnicas de coleta, preservação e herborização de material botânico. Instituto de Botânica, São Paulo, pp. 17-20.

Milanez, A.I. \& Trufem, S.F.B. 1981. Ficomicetos em frutos submersos do Parque Estadual das Fontes do Ipiranga. Rickia 9: 7-15.

Milanez, A.I. \& Trufem, S.F.B. 1984. Fungos zoospóricos em frutos submersos do Parque Estadual das Fontes do Ipiranga, São Paulo, II. Rickia 11: 77-84.

Milanez, A.I., Pires-Zottarelli, C.L.A. \& SchoenleinCrusius, I.H. 1994. Fungos aquáticos da região de Mata Atlântica do Estado de São Paulo. Anais da Academia de Ciências do Estado de São Paulo II: 142-149.

Milanez, A.I.; Pires-Zottarelli, C.L.A. \& SchoenleinCrusius, I.H. 1996. Criptógamos do Parque Estadual das Fontes do Ipiranga, São Paulo, SP. Fungos, 5: Leptomitales (Rhipidiaceae). Hoehnea 23: 67-76.

Miranda, M.L. \& Pires-Zottarelli, C.L.A. 2008. O gênero Pythium no Parque Estadual da Serra da Cantareira, Estado de São Paulo, Brasil. Hoehnea 35: 281-288.

Pires-Zottarelli, C.L.A. 1999. Fungos zoospóricos dos vales dos rios Moji e Pilões, região de Cubatão, São Paulo, SP, Brasil. Tese de Doutorado, Universidade Estadual Paulista, Rio Claro.

Pires-Zottarelli, C.L.A. \& Gomes, A.L. 2007. Contribuição para o conhecimento de Chytridiomycota da "Reserva Biológica de Paranapiacaba", Santo André, SP, Brasil. Biota Neotropica 3: 309-329. 
Pires-Zottarelli, C.L.A. \& Rocha, M. 2007. Novas citações de Chytridiomycota e Oomycota para o Parque Estadual das Fontes do Ipiranga (PEFI), SP, Brasil. Acta Botanica Braslica 21: 125-136.

Pires-Zottarelli, C.L.A., Gomes, A.L., Oliveira, J. M. \& Milanez, A.I. 2007. Phragmosporangium uniseriatum in Brazil. Mycotaxon 102: 179-182.

Pires-Zottarelli, C.L.A., Milanez, A.I., SchoenleinCrusius, I.H. \& Lohmann, L.G. 1996. Criptógamos do Parque Estadual das Fontes do Ipiranga, São Paulo, SP. Fungos, 4: Saprolegniales. Hoehnea 23: 39-66.

Rocha, J.R.S. 2002. Fungos zoospóricos em área de cerrado no Parque Nacional de Sete Cidades, Piauí, Brasil. Tese de Doutorado, Universidade de São Paulo, São Paulo.

Rocha, A.A. \& Costa, J.P.O. 1998. A Reserva da Biosfera da Mata Atlântica e sua aplicação no Estado de São Paulo. Governo do Estado de São Paulo, São Paulo.

Rocha, M. \& Pires-Zottarelli, C.L.A. 2002. Chytridiomycota e Oomycota da Represa do Guarapiranga. São Paulo, SP. Acta Botanica Brasilica 16: 287-309.
Rogers, A.L. \& Beneke, E.S. 1962. Two new species of Achlya in Brazil. Rickia 1: 243-249.

Rogers, A.L., Milanez, A.I. \& Beneke, E.S. 1970. Additional aquatic fungi from São Paulo state. Rickia 5: 93-110.

Schoenlein-Crusius, I.H., \& Milanez, A.I. 1989. Sucessão fúngica em folhas de Ficus microcarpa L.f. submersas no lago frontal situado no Parque Estadual das Fontes do Ipiranga, São Paulo, SP. Revista de Microbiologia 20: 95-101.

Schoenlein-Crusius, I.H., Pires-Zottarelli, C.L.A., Milanez, A.I. 1992. Aquatic fungi in leaves submerged in a stream in the Atlantic rainforest. Revista de Microbiologia 23: 167-171.

Scott, W.W. 1961. A revision of the genus Aphanomyces. Technical Bulletin Virginia Agricultural Experiment Station 151: 1-95.

Seymour, R.L. 1970. The genus Saprolegnia. Nova Hedwigia 19: 1-124.

Sparrow Jr., F.K. 1960. Aquatic Phycomycetes. University of Michigan Press. 2 ed. Ann Arbor. 


\section{Hoehnea}

Print version ISSN 0073-2877

\section{Hoehnea vol.39 no.2 São Paulo Jan/Mar 2012-10-09}

\section{Errata fornecida pelos autores referente ao artigo publicado na Revista Hoehnea 39(1): 95-} 112.

Título do Artigo: Oomicetos do Parque Estadual da Serra da Cantareira, São Paulo, SP, Brasil Autoria: Maria Luiza de Miranda e Carmen Lidia Amorim Pires-Zottarelli

Na página 101, $1^{\circ}$ coluna, onde se lê: Figura 15, leia-se: Figuras 15-16.

Na página 101, $2^{\circ}$ coluna, onde se lê: Figuras 16-18, leia-se: Figuras 17-19.

Na página 103, $1^{\circ}$ coluna, onde se lê: Figuras 19-20, leia-se: Figuras 20-21.

Na página 103, $1^{\circ}$ coluna, onde se lê: Figura 21, leia-se: Figura 22.

$\mathrm{Na}$ página 103, $2^{\circ}$ coluna, onde se lề: Figura 22-23, leia-se: Figura 23.

\section{Na página 102, legenda, onde se lê:}

Figuras 13-18. Oomicetos do Parque Estadual da Serra da Cantareira. 13-14. Plectospira myriandra Drechsler. 13. Zoosporângios lobulados formando complexos. 14. Oogônios com oósporos subcêntricos e anterídios envolvendo os mesmos. 15. Achlya apiculata de Bary. Aspecto geral dos oogônios no talo. 16-18. Achlya caroliniana Coker. 16. Oogônios lisos e papilados com oosferas. 17. Oogônio com oosfera e anterídio exígino. 18. Oogônio com oósporo excêntrico. Barras $=10$ $\mu \mathrm{m}$.

Figures 13-18. Oomycetes from the Parque Estadual da Serra da Cantareira. 13-14. Plectospira myriandra Drechsler. 13. Lobulate zoosporangia in complex. 14. Oogonia with subcentric oospores and antheridia surrounding them. 15. Achlya apiculata de Bary. Oogonia in the thallus. 16-18. Achlya caroliniana Coker. 16. Smooth and pappilate oogonia with oospheres. 17. Oogonium with oospheres and exiginous antheridium. 18. Oogonium with eccentric oospore. Bars $=10 \mu \mathrm{m}$.

\section{Leia-se:}

Figuras 13-18. Oomicetos do Parque Estadual da Serra da Cantareira. 13-14. Plectospira myriandra Drechsler. 13. Zoosporângios lobulados formando complexos. 14. Oogônios com oósporos subcêntricos e anterídios envolvendo os mesmos. 15-16. Achlya apiculata de Bary. 15. Aspecto geral dos oogônios no talo. 16. Oogônio apiculado com oósporos subcêntricos. 17-18. Achlya caroliniana Coker. 17. Oogônios lisos e papilados com oosferas. 18. Oogônio com oosfera e anterídio exígino. Barras $=10 \mu \mathrm{m}$.

Figures 13-18. Oomycetes from the Parque Estadual da Serra da Cantareira. 13-14. Plectospira myriandra Drechsler. 13. Lobulate zoosporangia in complex. 14. Oogonia with subcentric oospores and antheridia surrounding them. 15-16. Achlya apiculata de Bary. 15. Oogonia in the thallus. 16. Apiculate oogonium with subcentric oospores. 17-18. Achlya caroliniana Coker. 17. Smooth and pappilate oogonia with oospheres. 18. Oogonium with oospheres and exiginous antheridium. Bars $=$ $10 \mu \mathrm{m}$.

\section{Na página 104, legenda, onde se lê:}

Figuras 19-24. Oomicetos do Parque Estadual da Serra da Cantareira. 19-20. Achlya flagellata Coker. 19. Talo evidenciado zoosporângio vazio e oogônios em formação. 20. Oogônio com oosferas e anterídios díclinos. 21. Achlya klebsiana Pieters. Oogônio com oósporos excêntricos e anterídios díclinos. 22-23. Achlya orion Coker \& Couch. 22. Oogônio com oosferas e pedúnculo retorcido. 23. Oogônios com oósporos excêntricos e anterídios. 24. Achlya oviparvula Rogers \& 
Beneke. Aspecto geral do talo com oogônios e oosferas em processo de maturação. Barras $=10 \mu \mathrm{m}$ para as figuras 19,21, 22, 23 e 24. Barras $=20 \mu \mathrm{m}$ para a figura 20.

Figures 19-24. Oomycetes from the Parque Estadual da Serra da Cantareira. 19-20. Achlya flagellata Coker. 19. Empty zoosporangium and oogonia in formation. 20. Oogonium with oospheres and diclinous antheridia. 21. Achlya klebsiana Pieters. Oogonium with eccentric oospores and diclinous antheridia. 22-23. Achlya orion Coker \& Couch. 22. Oogonium with oospheres and twisted stalk. 23. Oogonia with eccentric oospores and antheridia. 24. Achlya oviparvula Rogers \& Beneke. Thallus with oogonia and oospheres in maturation. Bars $=10 \mu \mathrm{m}$ to the figures $19,21,22$, 23 and 24 . Bars $=20 \mu \mathrm{m}$ to the figure 20 .

\section{Leia-se:}

Figuras 19-24. Oomicetos do Parque Estadual da Serra da Cantareira. 19. Achlya caroliniana Coker. Oogônio com oósporo excêntrico. 20-21. Achlya flagellata Coker. 20. Talo evidenciado zoosporângio vazio e oogônios em formação. 21. Oogônio com oosferas e anterídios díclinos. 22. Achlya klebsiana Pieters. Oogônio com oósporos excêntricos e anterídios díclinos. 23. Achlya orion Coker \& Couch. Oogônio com oosferas e pedúnculo retorcido. 24. Achlya oviparvula Rogers \& Beneke. Aspecto geral do talo com oogônios e oosferas em processo de maturação. Barras $=10 \mu \mathrm{m}$ para as figuras 19, 21, 22, 23 e 24. Barras $=20 \mu \mathrm{m}$ para a figura 20.

Figures 19-24. Oomycetes from the Parque Estadual da Serra da Cantareira. 19. Achlya caroliniana Coker. Oogonium with eccentric oospores. 20-21. Achlya flagellata Coker. 20. Empty zoosporangium and oogonia in formation. 21. Oogonium with oospheres and diclinous antheridia. 22. Achlya klebsiana Pieters. Oogonium with eccentric oospores and diclinous antheridia. 23. Achlya orion Coker \& Couch. Oogonium with oospheres and twisted stalk. 24. Achlya oviparvula Rogers \& Beneke. Thallus with oogonia and oospheres in maturation.

Bars $=10 \mu \mathrm{m}$ to the figures 19,21,22, 23 and 24. Bars $=20 \mu \mathrm{m}$ to the figure 20. 